\title{
Turismo e Inclusão Social: percepção das comunidades locais da Área de Proteção Ambiental Jenipabu - Rio Grande do Norte (RN), Brasil
}

\author{
Tourism and Social Inclusion: perception of local communities in the Environmental \\ Protection Area of Jenipabu (Área de Proteção Ambiental Jenipabu) - Rio Grande do \\ Norte (RN), Brazil
}

\author{
Wagner Araújo Oliveira (OLIVEIRA, W.A.) ${ }^{1}$ \\ Kerlei Eniele Sonaglio (SONAGLIO, K.E.) ${ }^{2}$
}

\begin{abstract}
RESUMO - O presente trabalho tem como objetivo central investigar a percepção das comunidades do entorno da Área de Proteção Ambiental de Jenipabu - APAJ acerca da dinâmica do desenvolvimento do turismo e dos temas relacionados à inclusão social. Para tanto, a pesquisa adotou uma abordagem qualitativa, sendo de caráter exploratório e descritivo. Como instrumento de coleta de dados foi utilizado a aplicação de roteiros de entrevistas semiestruturados, tendo como população do estudo atores socais aliados a atividade turística. Para apreciação dos dados, fez-se o uso do método de análise de conteúdo baseado nas dimensões da inclusão social no turismo desenvolvidas pelos os autores Sancho (2007) e Irving (2010). A partir dos resultados foi possível perceber que a promoção da inclusão social no turismo na APAJ estava atrelada, exclusivamente, a capacidade da atividade em gerar emprego e renda, sobretudo com a criação de novos postos de trabalhos que o mercado turístico oferece. Nesse sentido, permite-se afirmar que a concepção desse conceito impera em uma abordagem majoritariamente econômica e num discurso reducionista. Entende-se que o ideal da promoção da inclusão social, estabelecida pela corrente teórica na qual se ancora este trabalho, prevê uma visão que supera esse conceito reducionista, ou seja: propõe mais integração entre os atores socais envolvidos com o turismo, garantia de direitos sociais e participativos, prática da cidadania, participação ativa no processo de planejamento e gestão, a distribuição equitativa de benefícios e novas oportunidades de inserção no mercado de trabalho com melhorias de qualidade de vida.
\end{abstract}

Palavras-chave: Turismo; Áreas Naturais Protegidas; Inclusão Social.

ABSTRACT - The main objective of this paper was to investigate the perception of the communities surrounding the Environmental Protection Area of Jenipabu (Área de Proteção

\footnotetext{
${ }^{1}$ Bacharelado em Turismo pela Universidade Federal do Rio Grande do Norte (UFRN), Especialização em Gestão Ambiental pelo Instituto Federal do Rio Grande do Norte (IFRN) e Mestrado em Turismo pelo Programa de Pósgraduação em Turismo - PPGTUR (UFRN). Professor substituto do Departamento de Turismo da Universidade Federal de Sergipe (UFSE), Campus São Cristovão - SE. Endereço Físico para correspondência: Rua Arnaldo de Souza Pereira, 568, Ponto Novo. CEP: 49047-006, Aracaju, Sergipe. E-mail: wagnercnrn@hotmail.com

${ }^{2}$ Bacharelado em Turismo pelo Instituto Superior de Turismo e Hotelaria (ESTH), Mestrado e Doutorado em Engenharia Ambiental pela Universidade Federal de Santa Catarina (UFSC). Professora Associado I da Universidade de Brasília (UnB) e atua como professora permanente no Programa de Pós-Graduação em Turismo (PPGTUR) da Universidade Federal do Rio Grande do Norte (UFRN). Endereço físico para correspondência: SQN 212, Bloco C, apartamento 601, Bairro Asa Norte. CEP: 70864030, Brasília/DF. E-mail: kerleisonaglio@gmail.com
} 
Ambiental de Jenipabu - APAJ) about the dynamics of tourism development and issues related to social inclusion. Then, the research adopted a qualitative approach, being exploratory and descriptive. As instrument of data collection, it was used the application of scripts of semistructured interviews, having as the population of the study social partners linked to the tourism activity. In order to evaluate the data, the content analysis method was used based on the dimensions of social inclusion in the tourism developed by the authors Sancho (2007) and Irving (2010). From the results it was possible to observe that the promotion of social inclusion in the APAJ tourism was exclusively linked to the capacity of the activity in generating employment and income, especially with the creation of new jobs that the tourism market offers. In this sense, it is possible to affirm that the conception of this concept prevails in a purely economic approach, that is, a reductionist discourse. It is understood that the ideal of the promotion of social inclusion, established by the theoretical current carried out in this work provides a vision that overcomes this reductionist concept. Then it is proposed a greater social integration among the social actors involved with the tourism, the guarantee of social and participative rights, the practice of citizenship, the active participation in the planning and management process, the equitable distribution of benefits and new opportunities for insertion in the labor market with improvements in quality of life.

Key words: Tourism; Natural Protected Areas; Social Inclusion. 


\section{INTRODUÇÃO}

A designação de áreas ou fragmentos de território para a proteção de recursos naturais, por razões religiosas ou culturais, é uma prática humana relativamente antiga e amplamente propagada. Hoje, a estratégia de definir espaços naturais protegidos está presente na legislação de diversos países, porém, não está mais fundamentada em conceitos religiosos ou culturais e sim expressa abertamente a intenção de garantir a existência de ecossistemas, espécies, genes, paisagens e culturas (IRVING, 2004; DIEGUES, 2001).

Nesse sentido, o estabelecimento de áreas naturais protegidas é umas das alternativas mais utilizadas para a conservação da natureza, pois é uma estratégia que visa combater o uso desenfreado e predatório dos recursos naturais por parte da sociedade. O que se tem percebido é que o processo de implantação dessas áreas tem enfrentado diversos desafios em todas as etapas de implementação, parte disso está diretamente relacionado ao processo de criação e gestão das áreas. Vale destacar que muitos dos desafios estão imbuídos na vertente social, principalmente no que cerne as questões da permanência das comunidades locais no interior e no entorno das áreas, pois nesse processo as comunidades são atores considerados mais vulneráveis uma vez em que essas mantêm uma relação intensa com os ambientes naturais, dependendo desta para sua sobrevivência e, também, para manutenção das suas representações sociais.

No que tange a permanência de populações humanas no interior ou no entorno das áreas protegidas é um tema de diversos estudos acadêmicos e debates no âmbito das políticas públicas, no Brasil e no mundo. É possível afirmar que há diversos problemas e conflitos existentes na relação áreas protegidas/populações locais, sobretudo as tradicionais. Em geral, as populações tradicionais não são "destruidoras da natureza", principalmente quando dependem da reprodução contínua dos recursos naturais renováveis para sua sobrevivência e quando o sistema de produção em que estão inseridas não é marcado pela rápida acumulação de capital (DIEGUES, 1996).

Contudo, percebe-se que o discurso dos órgãos ambientais tenta promover a inclusão social das populações no contexto das áreas protegidas, visando o turismo como uma das alternativas. Para tanto, a atividade turística tem que ser pensada de modo que contribua para reaproximar as populações tradicionais das áreas protegidas, porém em alguns casos tem afastado ainda mais esses grupos populacionais do processo de gestão do patrimônio natural e cultural. Mas o desenvolvimento do turismo pode contribuir para o desenvolvimento de uma 
região, dependendo da forma como é concebido e gerido. Na busca por uma iniciativa que consiga aliar o desenvolvimento do turismo com a proteção do patrimônio natural e cultural e, também, distribuir os benefícios econômicos nas regiões visitadas, diversas experiências vêm sendo realizadas pelo mundo, como alternativa ao turismo global, ao mesmo tempo em que surge uma demanda interessada por essa nova opção. Umas das experiências que pode ser citada como exemplo é o modelo de gestão do turismo de base comunitária desenvolvido na Prainha do Canto Verde no Ceará, onde o objetivo é promover a organização comunitária, o desenvolvimento local e a co-gestão a partir de práticas democráticas e solidária (SILVEIRAJUNIOR; BOTELHO, 2011).

Nesse sentido, o presente trabalho tem como objetivo central investigar a percepção das comunidades do entorno da Área de Proteção Ambiental Jenipabu acerca da dinâmica do desenvolvimento do turismo e dos temas relacionados à inclusão social. Para tanto, a pesquisa adotou uma abordagem qualitativa, sendo de caráter exploratório e descritivo. Como instrumento de coleta foi utilizado a aplicação de roteiros de entrevistas semiestruturados, tendo como população do estudo atores socais aliados a atividade turística. Para apreciação dos dados, fez-se o uso do método de análise de conteúdo baseado nas dimensões da inclusão social no turismo, desenvolvidas pelos os autores Sancho (2007) e Irving (2010).

\section{TURISMO E INCLUSÃO SOCIAL NO ÂMBITO DAS UNIDADES DE CONSERVAÇÃO}

A natureza e seus recursos são atrativos turísticos cada vez mais comuns na sociedade e, consequentemente, as áreas protegidas vêm sendo espaços recreativos, se posicionando como destinos turísticos de moda capazes de satisfazer a crescente demanda de visitação existente. Nesse cenário, um dos perigos reais é a banalização desses destinos e bens de uso comum. Não respeitando a capacidade de suporte do ambiente, bem como a preservação dos aspectos históricos culturais das comunidades. A atividade turística se apropria do espaço público, podendo transformar os destinos em "produtos étnicos", frutos do modismo de consumo da natureza, mudando os usos do lugar e provocando trocas culturais, assim como distribuição desigual da renda (DELGADO; PAZOS, 2013).

Portanto, o turismo nesses espaços deve ser organizado e planejado a partir da cooperação e sinergia entre os atores sociais, pois produz um valor social agregado intangível. O turismo é uma oportunidade de fortalecer as relações entre as pessoas que moram e convivem 
em uma mesma região. As pessoas têm a possibilidade de se mostrarem como realmente são, podendo relatar seus costumes, valores e sua história, e ainda agregar renda pela venda de serviços (MIELKE, 2009).

Nessa perspectiva, o desenvolvimento da atividade turística em UCs, pautado no planejamento adequado e com devida organização, pode se constituir em uma relevante alternativa para a conservação da biogeodiversidade, promoção da inclusão social e redução da pobreza na sociedade contemporânea. Quanto ao planejamento e o desenvolvimento do turismo em UCs, é importante que sejam pautados nos princípios da participação e inclusão social, de forma democrática e descentralizada, incluindo os diferentes atores sociais nos processos de tomadas de decisões. Dessa forma, as populações tradicionais no entorno e no interior das UCs têm a chance de uma inclusão social, por meio de sua inserção nas atividades ligadas ao turismo. Nesse sentido, é indispensável uma gestão eficiente vinculado a parcerias públicas e privadas visando proverem a infraestrutura necessária para que realmente possam influenciar de maneira positiva nas condições de vida dessas populações (OLIVEIRA, 2017).

As comunidades e suas organizações políticas vinculadas com o desenvolvimento do turismo vêm discutindo qual são suas contribuições e a dos parceiros da sociedade civil no processo de gestão e consolidação das UCs. Os resultados desse debate foram compilados por Abreu e Pinheiro (2012) citado por Queiroz Silva, no Seminário de Reflexão sobre a Categoria RESEX (WWF-Brasil, 2008), destacando as seguintes contribuições:

\section{QUADRO 1 - CONTRIBUIÇÃO DE CADA ENTIDADE NA GESTÃO DE UC}

\begin{tabular}{|c|c|}
\hline $\begin{array}{l}\text { COMUNIDADE } \\
\text { DA UC }\end{array}$ & $\begin{array}{l}\text { - Fortalecer a associação local, por meio de assembleias, encontros, oficinas e reuniões; } \\
\text { - Vigiar e zelar o patrimônio natural da UC; } \\
\text { - Manter atividades produtivas e extrativistas com qualidade e de acordo com Plano de Manejo; } \\
\text { - Oportunizar a capacitação do seu capital social; } \\
\text { - Participar das discussões sobre o Plano de Gestão e constituição do Conselho Gestor; e } \\
\text { - Informar-se sobre as políticas previstas para a UC. }\end{array}$ \\
\hline $\begin{array}{l}\text { ASSOCIAÇÃO } \\
\text { LOCAL }\end{array}$ & $\begin{array}{l}\text { - Representar os interesses das comunidades da UC; } \\
\text { - Identificar as demais entidades e estabelecer parcerias; } \\
\text { - Indicar as entidades para composição do Conselho Gestor; } \\
\text { - Acompanhar e opinar sobre a elaboração do Plano de Gestão da UC; } \\
\text { - Cobrar do órgão gestor a implementação das políticas previstas para a UC; } \\
\text { - Participar de eventos formativos e de intercâmbios; e } \\
\text { - Propor projetos/ convênios para seu fortalecimento institucional e extrativista/produtivo. }\end{array}$ \\
\hline $\begin{array}{l}\text { ENTIDADES } \\
\text { PARCEIRAS }\end{array}$ & $\begin{array}{l}\text { - Oportunizar a formação das lideranças de base e intercâmbios; } \\
\text { - Denunciar os descasos, violações de direitos civis, de posse da terra e cobrar a implementação } \\
\text { das políticas previstas para a UC; } \\
\text { - Indicar oportunidades de captação de recursos para projetos de fortalecimento institucional e } \\
\text { extrativista/ produtivo; } \\
\text { - Se fizer parte do Conselho Deliberativo, colaborar com as discussões da UC; e } \\
\text { - Apoiar as lideranças (Diretoria) da associação local. }\end{array}$ \\
\hline
\end{tabular}

FONTE: Elaboração própria compilada por Abreu e Pinheiro (2012) citado por Queiroz Silva 
Nesse quadro é possível averiguar, dentro da perspectiva de inclusão e participação social, a importância dada às comunidades no processo de planejamento e gestão do turismo em UCs. Portanto, na gestão participativa das UCs é preciso o envolvimento sistemático dos agentes sociais na tomada de decisão, mas esse processo é complexo e exige responsabilidade e interdependência dos envolvidos (AYRES; IRVING, 2006). De forma mais direta pode-se afirmar que uma gestão participativa garante sucesso quando gera impactos que atendam simultaneamente a interesses ecológicos e sócio-econômico-culturais.

Os processos participativos, além de serem diretrizes legais, são fundamentais para que os projetos desenvolvidos com comunidades habitadas em Unidades de Conservação (UCs) alcancem seus resultados com eficácia. Entretanto, a sua prática é um desafio. O diálogo de qualidade, que poderia ser alicerce para a qualificação da participação é muitas vezes desconhecido em seu significado e potencialidade. Caso a participação e o diálogo fossem instaurados, desde o início do processo de criação das UCs, talvez alguns dos graves conflitos que lhes são comuns, tais como: desmatamento criminoso, disputa de territórios, invasões ilegais, violência contra analistas ambientais. Neste caso, todas as ações contemplariam, implicitamente, a variável da legitima participação, com a aprendizagem social e o empoderamento comunitário (MINARI; RABINOVICI, 2014).

A interferência humana apresenta profunda complexidade quando se trata de manejo em áreas com exuberância de recursos naturais. As comunidades tradicionais apresentam uma interação maior com esse meio, diferente das urbanas, que cada vez mais estão se distanciando desse ambiente. As populações tradicionais desempenham um papel de fundamental importância para a preservação da diversidade ecológica. Respeitando sem dúvida, a diversidade cultural existente formando uma nova aliança entre homem e natureza (DIEGUES, 2000).

No tocante, ao processo de criação e gestão das UCs sem a devida preocupação com estudos que contempla a compreensão acerca do modo de vida e das relações sistêmicas entre as populações residentes e a natureza, juntamente com um planejamento coerente visando o desenvolvimento local tendo em vista as necessidades locais gera um cenário de conflitos.

Como mecanismo para garantir que as populações tradicionais sejam incluídas no processo de inclusão social no turismo, no âmbito das políticas públicas tem percebido uma intenção de considerar esse processo importante e a tentativa de elaborar ações e estratégias objetivando integrar o turismo e a natureza como uma alternativa para a inclusão social. 


\section{METODOLOGIA}

Para elaboração do presente estudo foi realizada a pesquisa bibliográfica em todo o processo investigatório, que consistiu em um levantamento de material teórico compreendido em livros, artigos, dissertações e teses, como também foi foi realizada uma pesquisa de campo.

A busca foi realizada no acervo da Biblioteca Central Zila Mamede, Biblioteca do Centro de Ciências Sociais Aplicadas (CCSA) e do Centro de Ensino Superior do Seridó (Ceres), da Universidade Federal do Rio Grande do Norte. Foram realizadas buscas em fontes de internet, como via Google Acadêmico, periódicos Coordenação de Aperfeiçoamento de Pessoal de Nível Superior (Capes). Também foi utilizada para busca a base digital de teses e dissertações. A busca resultou em textos selecionados e filtrados a partir de palavras-chave como: unidades de conservação/áreas naturais protegidas, turismo, gestão, planejamento e inclusão social.

A pesquisa adotou uma abordagem qualitativa, sendo de caráter exploratório e descritivo. Para coleta de dados foram aplicados roteiros de entrevista semiestruturada. Para desenvolvimento desse roteiro de entrevista foi levado em consideração as dimensões da inclusão social no turismo. Essas dimensões foram desenvolvidas pelos autores Sancho (2007) e Irving (2010), são estabelecidas 6 dimensões, a saber: política, ambiental, cultural, social, humana e trabalho. Para cada dimensão foi feita descrição dos temas de análise de acordo com a teoria estudada, com base nisso, foram elaboradas as questões, além disso o roteiro de entrevista foi elaborado com base no instrumento aplicado na pesquisa e Silva (2009).

A coleta de dados foi realizada entre 2016/2 e 2017/1 nas comunidades da Área de Proteção Ambiental Jenipabu (APAJ), Jenipabu, Redinha Nova e Santa Rita. Para realização de cada entrevista, foi feita a abordagem do entrevistado de modo respeitoso e onde ocorriam a apresentação e a explicação do objetivo da entrevista/pesquisa. Após esta etapa, se pedia a permissão para que a entrevista fosse gravada e para isso foi utilizado um aparelho smartfone. Quanto às durações das entrevistas, ficaram em média de 15 a 20 minutos.

Os roteiros de entrevistas foram aplicados junto aos empresários locais do turismo, pescadores, orientadores turísticos, presidentes de associações e representantes da sociedade da APAJ (Jenipabu, Redinha Nova e Santa Rita) e conselheiros da Conselho Gestor das respectivas APAs. A identificação dos entrevistados foi por meio de uma codificação afim de que os respondentes não tenham suas identidades reveladas e que fique claro qual segmento da comunidade ele faz parte. Desse modo, o código [A1] será utilizado para os empresários locais, 
[A2] pescadores, [A3] orientadores turísticos, [A3] presidentes de associações, [A4] representantes da sociedade civil e [A6] conselheiros do CG da APAs.

Para análise dos dados foi utilizada a técnica de análise de conteúdo, que de acordo com Bardin (2009), enquanto método torna-se um conjunto de técnicas de análise das comunicações que utiliza procedimentos sistemáticos e objetivos de descrição do conteúdo das mensagens. Sendo assim, a análise e interpretação dos resultados consistiu no levantamento dos principais depoimentos acerca de cada dimensão da inclusão social no turismo. Após cada dimensão foi feito um parágrafo conclusivo a partir do referencial teórico deste trabalho. Os resultados estão expostos na seção seguinte.

\section{4 ÁREA DE PROTEÇÃO AMBIENTAL DE JENIPABU}

A Área de Proteção Ambiental de Jenipabu foi criada através do Decreto Estadual $\mathrm{N}^{\circ}$ 12.620 de 17 de Maio de 1995, com o objetivo de ordenar o uso, proteger e preservar os ecossistemas de praias mata atlântica e manguezal, lagoas, rios e demais recursos hídricos, dunas e espécies vegetais e animais presente nos municípios de Natal e Extremoz. Com uma área de 1.881 hectares, a APA Jenipabu, assegurando a preservação ambiental de uma área de tabuleiros, bem como o importante complexo dunar de Jenipabu, região com intensa atividade turística (SECOM/IDEMA, 2014). O mapa 1 apresenta os limites da APA Jenipabu. 


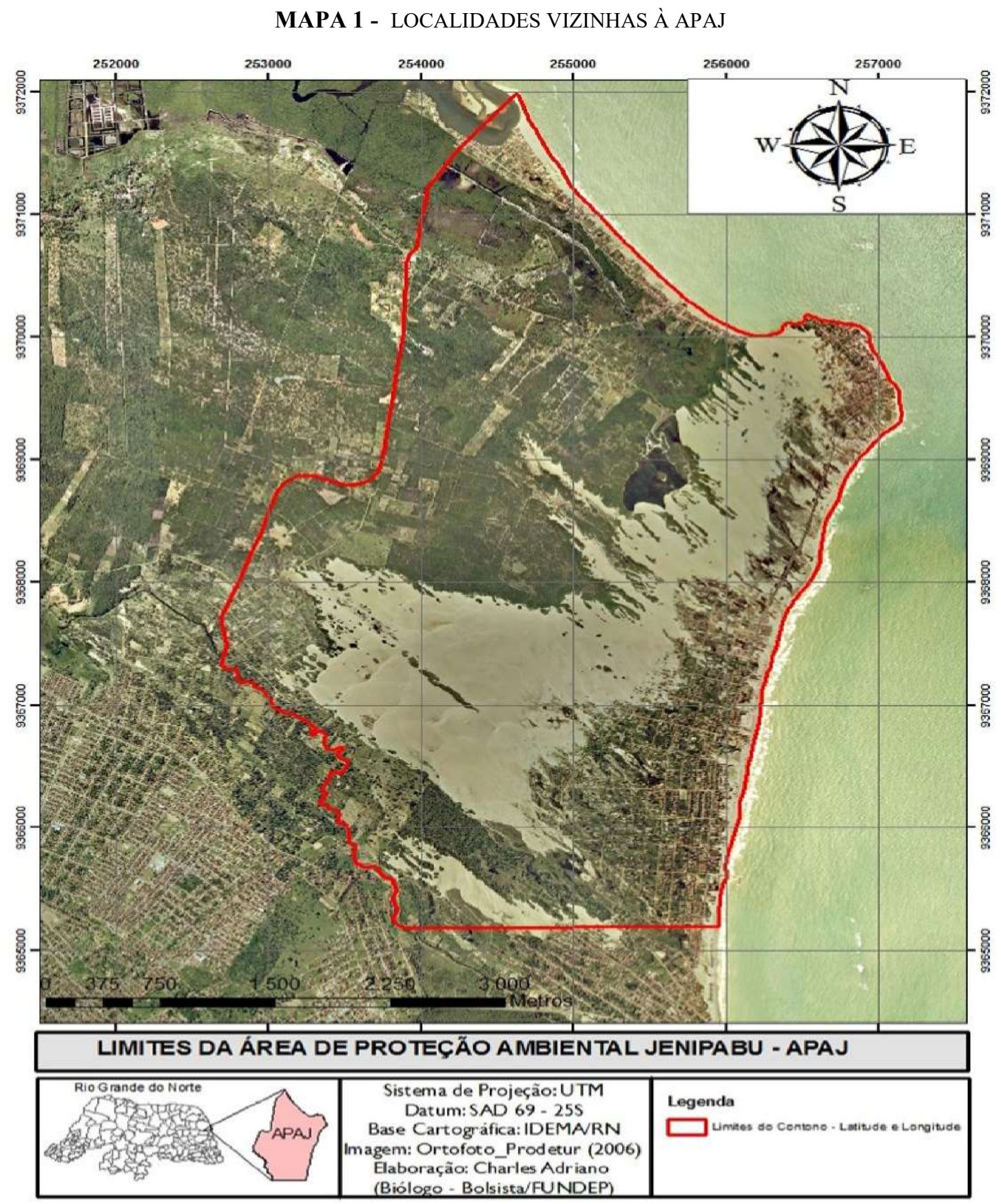

FONTE: SECOM/IDEMA, 2014.

O mapa anterioramente apresentado mostra a área do complexo dunar (contornada pela linha vermelha). Além disso é possível ver as comunidades que estão no entorno dos limites da APAJ e que sofrem influências direta do turismo. Nessa demarcação (em vermelho) estão concentrados os principais passeios turísticos, e consequemente os empreendimentos turísticos que fazem parte da cadeia produtiva do turismo.

Em termos de infraestrutura, esta unidade de conservação dispõe de uma sede, o Ecoposto, localizado no município de Extremoz/RN. O Ecoposto é um conjunto de três prédios 
em uma mesma área, composto por uma sede administrativa, uma casa do pesquisador e uma casa para alojamento da Companhia Independente de Proteção Ambiental - CIPAM (SECOM/IDEMA, 2014).

A APAJ possui um Conselho Gestor. Este colegiado foi instituído através do Decreto Estadual $N^{\circ} 19.139$ de 05 de Junho de 2006. O mesmo é formado por representantes de vários setores da sociedade, como o Instituto de desenvolvimento sustentável e meio ambiente (IDEMA), Secretaria Estadual de Turismo (SETUR), representante do segmento das empresas de hospedagens e de alimentação, representante dos prestadores de serviços de passeios de buggy, representantes de entidades de moradores das comunidades de natal e extremoz, inseridas na apa e em seu entorno imediato, representantes de entidades ambientalistas sediadas em cada município, Prefeituras dos municípios de Extremoz e Natal, Câmara de Vereadores dos municípios de Extremoz e Natal, Instituto Brasileiro do Meio Ambiente e dos Recursos Naturais Renováveis (IBAMA), Secretaria Patrimônio da União (SPU) e duas entidades de ensino e pesquisa que desenvolvam atividades na área da APAJ (SECOM/IDEMA, 2014).

A APAJ tem sua economia baseada na pesca artesanal, agricultura de subsistência, agropecuária e no turismo. Foi feito o destaque para atividade turística sendo considerada a principal atividade econômica desenvolvida no interior e no entorno da APAJ. A atividade turística na APAJ foi iniciada no final da década de 1980, no período da consolidação do Rio Grande do Norte como destino turístico no contexto nacional.

Inicialmente a atividade turística teve seu marco histórico com a criação do o Parque Turístico Ecológico Dunas de Genipabu Ltda, que confunde com a criação da APA de Jenipabu, pois a justificativa da criação da área protegida foi devido o avanço da atividade turística. $\mathrm{O}$ objetivo do Parque Ecológico era fomentar o potencial turístico. Por meio do Decreto Estadual $\mathrm{n}^{\mathrm{o}}$ 19.346/2006 ordenou e disciplinou o uso de veículos credenciados na área das Dunas de Jenipabu e estabeleceu o passeio de buggy sobre o campo de dunas da APAJ.

Após o avanço dos passeios de buggy, que foi o responsável pelo início da atividade turística, a praia de Jenipabu ganhou cada vez mais destaque, com isso o turismo se tornou uma atividade de expansão por meio da sua cadeia produtiva, representada pelas várias opções de passeios, serviços, alimentação e hospedagem. Atualmente, APA Jenipabu dispõem de um leque de atrativos, além de passeios de dromedários, cavalo, jangada, passeio de buggy, entre outros serviços que compõem o produto turístico do destino.

Dada a importância para atividade turística desenvolvida na APAJ e sua relação direta com as comunidades que ali se fazem presentes, viu-se a necessidade de investigar como a 
gestão e planejamento do turismo vem contribuindo ou não para a promoção da inclusão social, sendo assim o próximo tópico será abordado os resultados que foram levantados a partir da percepção dos moradores acerca do turismo e a inclusão social.

\section{RESULTADOS}

Este tópico ficou reservado para apresentar os resultados do objetivo deste trabalho que consiste em mostrar a percepção das comunidades do entorno acerca da inclusão social por meio da atividade turística. Portanto, como explicado na metodologia, foram aplicados questionários juntos aos atores sociais, com base nas seis categorias de inclusão social no turismo, a saber: cultural, ambiental, política, social, humana e trabalho.

\subsection{DIMENSÃO CULTURAL}

A primeira categoria a ser analisada será a cultural, essa é composta por dois principais temas, a saber: reconhecimento, valorização e fortalecimento das tradições, aspectos e costumes da população residente nos destinos turísticos e a proteção e conservação do patrimônio histórico artístico cultural das destinações turísticas. De modo geral, foi questionado aos respondentes sobre o reconhecimento do local por meio da frequência de visitas e atividades realizadas no entorno da APAJ e a representação e importância do local de modo individual e coletivo.

Foi possível averiguar que a população local tem acesso aos recursos naturais e turísticos, pois todos responderam que frequentam os locais, os moradores da APAJ em sua maioria realizam atividades como caminhadas nas dunas, acompanham amigos/turistas nos passeios turísticos, contemplação da paisagem, atividades diversas e para quem trabalha no complexo dunar, frequentam para realizar atividades do trabalho, como passeios de buggy, esquidunas, dromedários ou vendas variadas. Isso se torna importante para a promoção da inclusão social, uma vez em que mesmo com o desenvolvimento do turismo e o fluxo constante nos atrativos turístico as comunidades devem continuar visitando e tendo acesso aos recursos para a prática de lazer e recreação.

No tema Reconhecimento, valorização e fortalecimento das tradições da população residente nos destinos turísticos, foram feitas duas perguntas, a primeira, no sentido mais 
individual, o que o parracho ou dunas representa para você? E no sentido mais coletivo, você acha que o parracho ou as dunas são importantes?

Na APAJ, o complexo dunar é o principal recurso natural utilizado para comercialização e promoção turística do local, de Natal e do Estado. Desse modo, obtiveram-se várias respostas, para alguns, as dunas representam o desenvolvimento do turismo "Representa o turismo", "Para mim representa melhor lugar para o turismo[A5]", além disso, para alguns representa uma fonte de renda, uma vez que as dunas levaram o desenvolvimento do turismo, a partir disso, vários postos de trabalhos foram criados, e consequentemente, movimenta a economia local. Em algumas outras repostas foi possível perceber o sentimento de pertencimento, como: "Jenipabu para mim representa meu ninho [A5]”, “Jenipabu para mim é lugar que desejo ver muito bem conservado e preservado [A5]" e "Lugar legal para relaxar, louvar e é um lugar de tranquilidade[A5]", além de outras como "Ambientalmente é importante para o ecossistema, turisticamente falando cartão postal apesar de ser dunas de Santa Rita [A6]”.

Diante disso, é possível analisar que o sentimento de pertencimento das populações residentes nos destinos turísticos implica diretamente na valorização da identidade e no resgate da autoestima, elementos essenciais para compor o objetivo da inclusão social. Na APAJ foi possível resgatar dois depoimentos que comprovam essa discussão, tais como: “As dunas são importantíssima, a comunidade não existiria se não houvesse as dunas[A5]".

Por isso, é importante valorizar a atividade turística e o planejamento participativo. $\mathrm{O}$ modelo de desenvolvimento no turismo ainda é baseado nas ações do poder público e dos agentes de mercado que comandam de forma hegemônica a atividade, fazendo com que o residente enquanto agente ativo e participante da gestão e do planejamento do espaço turístico não é levada em consideração.

\subsection{DIMENSÃO AMBIENTAL}

A categoria ambiental écomposta pelos seguintes temas, Conservação dos recursos renováveis; Acesso a visão coletiva do patrimônio natural e Incentivo a adoção de práticas sustentáveis de conservação dos recursos não renováveis. Nessa categoria, houve perguntas no sentido de reconhecimento do que seria uma APA, se obtinha conhecimento que o local fazia parte de uma APA, bem como a sua importância, e se tinha acesso a informações das normas do local e se considerava que o local estava conservado. 
A primeira pergunta foi no sentido de investigar se os entrevistados sabiam o que seria uma Área de Proteção Ambiental, todos os respondentes afirmaram ter conhecimento do que seria uma APA, e, além disso, se sabiam que as dunas faz parte de uma área de proteção ambiental. Logo em seguida, foi questionada a importância disso para a conservação dos recursos naturais.

Sendo assim, foram resgatadas tais respostas: "Porque é preservar ne, porque se não vai acontecer várias coisas errada, desmatar, então é melhor preservar [A5]." "Importantíssimo, talvez se ela não fizesse parte dessa APA ela já não existia mais, não pela natureza e sim pela ação humana, pela próprias pessoas que utilizam dessa área indevidamente e incorretamente [A1]."“Para não depredar e manter mais tempo o patrimônio natural [A3]."

Diferente do cenário apresentado no processo de criação das UCs verificou-se que as comunidades têm conhecimento que o local onde moram faz parte de uma APA. Para chegar a esse nível de conhecimento, foi preciso considerável tempo para todos pudessem ter essa percepção e conhecimento sobre a importância da conservação. Isso mostra ser um resultado relevante uma vez que o conhecimento é disseminado, então é provável que as comunidades sejam conscientes que no local existem regras que devem ser cumpridas em favor da conservação, e que os próprios moradores possam se tornar potenciais agentes fiscalizadores, podendo verificar os usos inadequados nas localidades.

Logo, foi perguntado se consideravam que os locais estavam conservados. Por meio das respostas foi possível perceber que os moradores consideram que o local está conservado comparado com anos atrás, quando não existia nenhuma ação em prol da conservação, porém mesmo considerando o local conservado, ainda acham que muito poderia ser feito, sobretudo na fiscalização das dunas. A fiscalização nas dunas das APAJ é ausente, o que se torna uma prática importante para a manutenção e conservação dos recursos naturais, sobretudo, por ser uma área bastante vulnerável a impactos.

O que pode ser analisado nessa dimensão ambiental, que para compor na promoção da inclusão social do turismo em áreas naturais protegidas, é que o trabalho deve ser contínuo, realizando ações relacionadas a conscientização e sensibilização das comunidades sobre a importância da conservação do monumento natural, para o desenvolvimento da atividade turística. Essas ações devem comtemplar a valorização da produção local e o fortalecimento dos aspectos ligados ao patrimônio natural e pautados nos princípios da sustentabilidade.

Nesse sentido, é importante que o planejamento turístico possa facilitar a criação de programas que congreguem a geração de emprego e renda, mas que também possam incluir a 
valorização dos aspectos culturais das populações residentes, da conservação dos recursos naturais e adoção de práticas responsáveis ambientalmente.

\subsection{DIMENSÃO POLÍTICA}

Como terceira categoria do tema central da inclusão social, será realizada a discussão da dimensão política, que considerou temas como: formação cidadã no sentido de adquirir condições efetivas para participar e se fazer representar na esfera política; espaço para o exercício dos direitos e deveres do cidadão; descentralização de poder e das ações por parte dos órgãos governamentais; e acesso ao processo de tomada de decisão por todos os atores sociais envolvidos no desenvolvimento do turismo.

O primeiro questionamento realizado aos respondentes foi se tinham conhecimento de quem tomava as decisões acerca do que deveria ser feito ou não dentro da APA. Em sua maioria, responderam ser o Instituto de Desenvolvimento Sustentavel e Meio Ambiente (IDEMA), que é o órgão estadual responsável pela gestão das APAs. Ainda tiveram aqueles que responderam ser o IBAMA, pois associam esses dois órgãos como sendo apenas um, porém existe diferencias, o IBAMA é uma das instâncias de governança que faz parte do conselho gestor das APAs. Ainda foi possível regastar respostas citando ser a prefeitura dos municípios, como também a Marinha. O mais citado foi o IDEMA, devido está próximo das comunidades, e pelo fato de estar convocando e realizando as reuniões.

Logo, foi perguntando se a opinião da comunidade era levada em considerações nas tomadas de decisões sobre a APA. Dois respondentes da APAJ relataram de forma resumida sua consideração acerca do questionamento.

Nem sempre, muito pouco até porque a comunidade ela tem um processo de desgastes,
ausência de formação política, então a comunidade é muito leiga ainda, e as vezes não
compreende, até não participa das decisões, o momento em que a comunidade tem para
participação é durante as reuniões do conselho gestor da APA, e por muitas das vezes a
gente não ver uma participação direta da comunidade. Mas ela existe, inclusive a
comunidade de Santa Rita tem participado, pelo menos tem provocado. O nosso
conselho não é tão morto não, infelizmente nem sempre somos atendidos e respeitado
de fato como deveria ser dentro dessa gestão [A6].

De fato o que esse comentário revela é que existe o conformismo da parte da população em lutar a favor dos seus benefícios por meio da atividade turística, parte disso, está relacionado diretamente com o descrédito em relação ao poder público vir a considerar os interesses dos moradores. Pois o que prevalece em muitos casos é o poder público e os agentes de mercado que comandam de forma hegemônica a atividade. Assim como demostram os dois comentários 
a seguir:“É levada em consideração em termos, ela pode até ser ouvida, mas no final não decide, quem decide é quem está na gestão pública [A5]."; "Não, acho que não, quando a voz superior (poder público) fala mais alto ninguém tem direito [A5]."

Em outro comentário o respondente afirma da importância da comunidade ser ouvida, mas devido à falta de pensamento coletivo entre os envolvidos com a atividade turística recaem em limitações, principalmente em termos de investimentos para a comunidade.

Em todos os lugares, geralmente a opinião da comunidade é a chave para sair qualquer projeto, infelizmente aqui em Jenipabu não temos tanta essa harmonia, ente grupos de pessoas que moram aqui, uns pensam de uma forma outros de outra, e nunca chega a um consenso. Por isso temos poucos investimentos, nunca finaliza nossos investimentos, por isso, porque somos apáticos, deixando as coisas acontecer, meia dúzia de pessoas vão atrás, corre atrás e outras não [A6].

Em suma, o que foi possível perceber é uma população passiva, pois concordam as determinações dos agentes turísticos hegemônicos, no caso o poder público e o mercado, excluindo a possiblidade das comunidades se incluir como agente participativo, fazendo valer o seu direto.

Por fim, foi investigado se os respondentes participaram de alguma reunião que tratava de assunto referente ao turismo na APA. Em sua maioria participam ou participaram das reuniões realizadas pelo IDEMA ou pela prefeitura. Dos que participam, a participação média foi de três reuniões. Em seguida, foi perguntado se essas reuniões surtiram algum efeito do que foi debatido. Alguns responderam que sim, além disso, foi destacado o fato das reuniões serem um momento importante para debater ideias e também uma oportunidade de serem ouvidos.

Eu sou positiva, se ainda não estivesse elas ainda estaríamos pior. Em verdade as
pessoas reclamam muito, mas eu acredito que é através do processo democrático de
discussões de fóruns, que minimamente podemos "ta" junto, pior se não acontecesse.
Nós temos um pais que desde a Constituição é dado essa abertura, e realmente é preciso
que a gente de fato aproveite essa participação dentro desse processo democrático [A6].

Uns não acreditam que os encontros são proveitosos, pois nada que foi solicitado foi realizado. "As reuniões ficam muito na teoria e nada na prática [A1]". "Não acho proveitosa, não surtiram efeito, porque fica só na teoria, nada sai do papel, nada na prática, é raro sair do papel para prática, por exemplo, esse projeto de sinalização turística é, é necessário é, mas é mal feito, começou e não terminou, temos o pórtico, todos foram instalados, mas nenhum terminados [A4]."

É comum se deparar com depoimento dessa natureza, uma vez em que a morosidade é algo recorrente no poder público quanto as demandas que são solicitadas pela comunidade ou pelo conselho gestor. Portanto, o que se almeja é que as prioridades sejam executadas e que essas possam beneficiar todos os envolvidos, sobretudo, atender os anseios das comunidades. 


\title{
5.4 DIMENSÃO SOCIAL
}

Para esta dimensão, a social, foram selecionados temas que correspondem a benefícios e malefícios que o turismo pode gerar em uma determinada localidade, nesse sentido, foram feitos questionamentos se o turismo traz benefícios ou malefícios sociais e se o turismo deveria acabar ou continuar nas comunidades pesquisadas.

Para o primeiro entrevistado foi realizada uma pergunta se o turismo trazia alguns benefícios sociais para as comunidades. Observou-se nas respostas que considerável parte confundiram ou associaram benéficos sociais com os benéficos econômicos. Foi possível obter um depoimento esclarecedor que mostrou a lógica do real desenvolvimento do turismo nas comunidades.

\begin{abstract}
Na perspectiva social não, ainda não, muito pouco, porque o turismo ainda não tem o foco social, tem poucas empresas que tem essa visão que visa isso. $O$ turismo na vertente aqui, na verdade houve uma inversão de valores, porque o que a gente ouve dos mais velhos, que o turismo antes de está aqui com toda veemência, as pessoas eram mais sociáveis, tinha mais festas culturais, mais eventos, as pessoas eram mais ligada a igreja, especificamente a igreja católica que sempre esteve teve aqui. Pessoal diz que antes tinha uma pracinha, sentava, dialogava, tinhas festas tradicionais, e com a chegado do turismo, a gente observa que é muito resistente daqueles que ainda querem preservar as questões culturais e social, mas o turismo aqui leva mais para vertente do capital [A5].
\end{abstract}

Esse depoimento revela a lógica atual do desenvolvimento do turismo, como já mencionado anteriormente, o turismo segue pautado no desenvolvimento da lógica do mercado, centrando sempre na ideia do capitalismo. Além disso, vale ressaltar que, apesar de ser uma atividade econômica, o turismo pode ser praticado a partir da premissa da inclusão social. Porém, é comum ver a atividade turística sem o planejamento correto e uma organização devida, que consequentemente tem alavancado impactos nocivos as comunidades, pois há uma tendência a desvalorização das caraterísticas culturais das populações originais do lugar turístico.

Além disso, foi possível coletar vários depoimentos que inferem essa visão na qual o turismo só traz benéficos econômicos, quando perguntado quais benefícios sociais o turismo poderia trazer. Obteve-se as seguintes respostas: "Fonte de renda [A1]"; " Empregos e renda [A2]”; “Financeiro, na medida em que o turismo vem e faz divulgação da área. E tem resultado para a pessoa que vive aqui do turismo [A5]."; "Ajuda principalmente financeira para comunidade, o turismo é a chave daqui de Jenipabu, ajuda muito [A5]”.

Em seguida, ao perguntar se o turismo trazia algo de ruim, foram forncedidas respostas como: "Lixo, unir mais e ajudar mais o local [A2]”;“ É o lixo é o maleficio maior [A2]”; 
"Violência e roubo, como não tem segurança, piora um pouco [A1]".; e "Degradação do ambiente, da cultura [A6]".

Logo, foi perguntado se o turismo deveria acabar, e por unanimidade, responderam que não, sendo que a principal justificativa para não acabar, é devido atividade turística ser a principal atividade de contribui para a geração e emprego e renda para as comunidades.

Vale ressaltar que o discurso político expressa uma visão propensa e otimista quanto o potencial do turismo para a promoção da inclusão social por meio dos benefícios sociais, na tentativa de combater as desigualdades sociais, à pobreza, violência, fome e exploração sexual. No entanto, a efetivação e a execução das políticas públicas de turismo e da natureza deixam a desejar, pois é ainda é um tema abordado de forma superficial.

\subsection{DIMENSÃO HUMANA}

Esta categoria reuniu questionamentos acerca dos seguintes temas: educação como meio de inserção no mercado de trabalho; acessibilidade a novas tecnológicas; acesso aos meios de créditos; investimento na melhoria das infraestruturas básicas e turísticas.

O primeiro questionamento realizado foi se o respondente já teve oportunidade de participar de algum curso na área do turismo. Os respondentes já participaram de cursos voltados para o turismo em diversas áreas, como alimentos, atendimento ao cliente, recepção, hotelaria, turismo sustentável, vendas e hospitalidade. Alguns cursos foram de iniciativas de prefeituras locais, através do Sebrae e Senai e outros por iniciativa própria.

Foi possível entrevistar dois bacharéis em turismo, uma formada pela Universidade Estadual do Rio Grande do Norte e outro pela Universidade Potiguar, ambos são empresários no ramo do turismo, uma na área de passeios turísticos e outro na área de alimentos e bebidas. Os turismólogos afirmaram que se qualificaram após já terem iniciado suas atividades profissionais na área do turismo, logo, viram a necessidade de se capacitar e resolveram fazer um curso superior na área.

A promoção de ações de qualificações na área do turismo se torna um elemento essencial para que consiga atingir o objetivo da inclusão social. Uma vez existindo a capacitação da população local facilita a inserção do mercado de trabalho, e, além disso, garante novas oportunidades profissionais, podendo ser por meio de postos de trabalho como também pelo empreendedorismo. 
Em seguida foi possível investigar se os respondentes já tiveram oportunidade de participar de alguma linha de financiamento para aquisição de equipamento e modernização dos equipamentos turísticos ou setores de crédito para impulsionar sua atividade econômica. No caso da APAJ de Jenipabu, a empreendedora local já participou relatando que "Já, participamos, junto a IDEMA e Boticário, mas não foi comtemplado, o Banco do Nordeste com apoio, ações voltadas para turismo ambiental [A1]". Outra empreendedora local na área de hospedagem relatou que "Quem mais chega aqui é o Banco do Nordeste, já fizeram alguma linda de crédito para os comerciantes, o CredAmigo, fizemos conscientização para cadastro de micro empresas, para fortalecer os comércios [A1]".

Alguns respondentes falaram da dificuldade de conseguir devido a burocracia e a falta de equidade na participação dos setores créditos, comparando com os empresários de grande porte e comerciantes de comunidades locais.

Eu acho que temos bons setores de créditos de turismo, o que precisa é ser bem direcionado, o que não pode é um hotel da Via Costeira receber milhões, e um coitado aqui da comunidade não conseguir 50 mil para revitalizar sua empresa. O ordenamento desse setor deveria ser voltado de uma maneira mais correta [A5].

"[A4] Sim, temos grandes financiadores que é o Bradesco e Caixa, e a dificuldade é a burocracia que isso impede que qualquer um comerciante conseguir financiamento".

Todavia, o Ministério do Turismo assim como alguns Bancos, por meio das políticas públicas, oferecem linhas de financiamento destinadas a aquisição ou modernização de utensílios e equipamento para o turismo, como pode ser citado o Fundo de Financiamento do Centro-Oeste Empresarial - Turismo Regional (FCO); Cartão BNDES; BNDES Automático; Financiamento para Aquisição de Máquinas e Equipamentos (Finame); Financiamento a Empreendimentos (Finem); Fundo Geral do Turismo (Fungetur) ; PROGER Turismo; Programas de Financiamento ao Turismo Sustentável; Programa de Apoio ao Turismo Regional (Proatur); e o Programa de Financiamento a Aquisição Isolada de Matérias-Primas e Mercadorias .

Em documento registra-se por meio dos Planos Nacionais do Turismo, inclusive o mais atual, lançando em 2018, ações voltadas a incrementar as linhas de financiamento à iniciativa privada através do desenvolvimento de parcerias com instituições financeiras, entidades privadas e órgãos públicos, buscando a ampliação dos recursos e a adequação de linhas de crédito para o financiamento das atividades dos prestadores de serviços turísticos e do público final.

Por fim, para encerrar a análise da categoria foi investigado se os entrevistados conheciam alguma política pública de turismo (municipal, estadual e federal) com 
investimentos e ações destinados à implantação, revitalização e modernização da infraestrutura básica e turística.

Na APA Jenipabu foi possível levantar duas ações em prol do turismo, primeiro é na praia de Jenipabu, o projeto Orla, que tem como objetivo a reurbanização da orla da praia, construção do calçadão e quiosques. Devido a burocracia da liberação de recursos financeiros e contratação de empresa para a operacionalização foi interrompida para um tempo, logo, foi iniciado as obras com garantia do término de um ano. Outra ação realizada é a sinalização turística de todos os municípios que fazem parte da APAJ, mas não foi dado início ao projeto, os motivos não se sabem. E como projeto para infraestrutura básica a ação realizada foi o saneamento básico da praia de Jenipabu, porém sem conclusão.

Para que o desenvolvimento do turismo aconteça de forma adequada e satisfatória para os turistas e comunidade, é necessário que o planejamento contemple melhorias de infraestrutura básica e turística de modo que haja expansão dos benefícios socioeconômicos.

\subsection{DIMENSÃO TRABALHO}

Por fim, a última dimensão a ser analisada foi a do trabalho. Nessa reuniu questionamentos referentes a oferta de empregos e postos de trabalhos na área do turismo. A importância do turismo para a economia local é atrelada a capacidade que a atividade tem de gerar emprego e renda para a população, prova disso é que a maior atribuição dada a atividade turística é ser uma atividade que amplia as oportunidades de ganhos econômicos.

Pensando nisso foi investigado quais os principais postos de trabalhos, a satisfação dos empregos e a importância do turismo para a economia local. Inicialmente foi questionada a quantidade de pessoas da família que trabalham e quantas na área do turismo. Na APAJ foi possível investigar que a média de pessoas que trabalham em cada família foi entre 2 a 3 pessoas, na área do turismo ficando a mesma média, pois atividade turística é a que mais gera empregos.

Também levantou-se diversos postos de trabalhos, em destaque foram empregos na área de alimentos e bebidas, restaurantes e quiosques, postos de trabalho que mais oferecem empregos a população local. Em seguida o trabalho mais citado foi os passeios turísticos, tais como passeios de buggy e dromedários. Em sua maioria mostraram estar satisfeitos com as condições de trabalhos.

Apenas existiu um relato que mostrou insatisfação, a saber: 
Poderia acrescentar em questões de infraestrutura, para o pessoal tem acesso a caixas eletrônicos. Tem mais segurança. Apesar de ser bastante explorado não tem infraestrutura, o cliente chega com cartão de credito, quer sacar não tem caixa eletrônico. Poderia ter feiras de artesanatos [A1].

As comunidades das ambas APAs não oferecem serviço de caixa eletrônico devido a ausência de segurança nas localidades, uma vez instalado caixa eletrônico fica mais suscetível a assaltos. Outro relato levantado tem relação com a falta de divulgação dos destinos turísticos "Não, poderia melhorar nosso ponto de trabalho e material de divulgação [A2]."

Outro fato que foi possível observar é que existe uma insatisfação quanto a permanência dos turistas nas comunidades, pois os turistas estão apenas de passagem quando realizam o passeio do buggy ou quando no passeio nos recifes de corais, após o término do almoço retornam para Natal, sem ter a oportunidade de permanecer mais na comunidade e poder movimentar mais a economia local.

Em seguida foi investigada a principal atividade que provia a renda familiar, e por unanimidade, foi o turismo, pois como já mencionado anterior, é a principal atividade econômica e a que mais gera emprego, apesar da maioria dos postos de trabalhos concentrarem de menor qualificação e remuneração, tais como: garçons, cozinheira, auxiliar de cozinhar, auxiliar de serviços gerais e camareira. A comunidade está inserida nesses por falta de qualificação, tem se enquadrado nesse contexto e ganhado salários desvalorizados, apesar de que o turismo trouxe mais estabilidade financeira, comparada com as demais atividades que já eram praticadas antes do turismo, como agricultura e pesca.

A questão da criação, do aumento e da manutenção dos postos de trabalhos advindos do turismo é considerada uma das principais prioridades nas políticas públicas de turismo. Elas sempre procuram evidenciar a importância e o potencial que a atividade tem quanto a geração de emprego e renda. O que prova a capacidade do turismo é capaz de gerar emprego em torno de 50 segmentos da economia, e quando for planejada de forma adequada pode propiciar forte inclusão social e econômica no âmbito das comunidades locais.

\section{CONSIDERAÇÕES FINAIS}

O presente trabalho teve como objetivo central investigar a percepção das comunidades do entorno da APAJ acerca da dinâmica do desenvolvimento do turismo e dos temas relacionados à inclusão social 
O que foi observado a partir de tal análise é que o conceito de inclusão social no processo de planejamento e gestão do turismo na APAJ se distancia do que foi discutido nesse trabalho. O conceito da promoção da inclusão social está pautado em 6 dimensões, que são: política, ambiental, cultural, social, humana e trabalho. Dessa forma, pode-se afirmar que baseado nessas dimensões considera a inclusão social como um processo amplo que está diretamente relacionado com a relação entre os direitos da sociedade de modo que os cidadãs passem a assumir o papel central, decisivo e participativo no processo de planejamento e desenvolvimento do turismo.

Além disso possível observar que o conceito de inclusão social no turismo está atrelado, exclusivamente, da capacidade da atividade em gerar emprego e renda com a criação de novos postos de trabalhos que o mercado turístico oferece. Nesse sentido, permite-se afirmar que a concepção desse conceito impera em uma abordagem majoritariamente econômica e amparada num discurso reducionista. $\mathrm{O}$ ideal da promoção da inclusão social estabelecida pela corrente teórica utilizada nesse trabalho prevê uma visão que supera esse conceito reducionista. Ela propõe uma maior integração social entre os atores socais envolvido com o turismo, garantia de direitos sociais e participativos, prática da cidadania, participação ativa no processo de planejamento e gestão, a distribuição equitativa de benefícios e novas oportunidades de inserção no mercado de trabalho com melhorias de qualidade de vida. Além disso, a inclusão social envolve em seu conceito princípios básicos como acesso a educação, a serviços sociais, a saúde, a investimentos em infraestrutura básica e direitos políticos.

\section{REFERÊNCIAS}

ABREU, M. J. P.; PINHEIRO M. R. Participação da sociedade civil na gestão de unidades de conservação. Gestão de Unidades de Conservação: compartilhando uma experiência de capacitação. Realização: WWF-Brasil/IPÊ- Instituto de Pesquisas Ecológicas. WWF-Brasil. 2012.

AYRES, H. H. F; IRVING, M. A. O olhar psicossocial para a gestão participativa de áreas protegidas: refletindo sobre possibilidades e desafios. In: IRVING, M. A. (Org.) Áreas protegidas e inclusão social: construindo novos s ignificados. Rio de Janeiro: Aquarius, 2006. p. $77-90$.

BARDIN, L. Análise de Conteúdo. Lisboa, Portugal: Edições 70, 2009.

DELGADO, A. B. D; PAZOS, A. S. Interpretação do patrimônio, turismo e gestão de áreas protegidas: algumas aproximações. Revista Turismo \& Sociedade. Curitiba, v. 6, n. 2, p. 300323, 2013. 
DIEGUES, A. C. S. O mito moderno da natureza intocada. São Paulo: Hucitec, 1996.

DIEGUES, A. C., ARRUDA, R.S.V. Saberes tradicionais e biodiversidade no Brasil. Brasília: MMA, 2001.

DIEGUES, A.C.S. O mito moderno da natureza intocada. São Paulo: Ed. Hucitec, 2000. p.169.

IRVING, M. A. Áreas Protegidas e Inclusão Social: uma equação possível em políticas públicas de proteção da natureza no Brasil? Sinais Sociais, v.4, p.122-147, 2010.

IRVING, M. A.; MENDONÇA, T. C. M . Turismo de base comunitária: a participação como prática no desenvolvimento de projetos turístico no Brasil - Prainha Do Canto Verde, Beberibe (CE). Caderno Virtual de Turismo, v. 4, n. 4, p. 12-22, 2004.

MIELKE, E. J. C. Desenvolvimento Turístico de Base Comunitária. Campinas: Átomo \& Alínea, 2009.

MINARI, M.L.; RABINOVICI, A. Diálogo, participação e projetos de turismo com comunidades em Unidades de Conservação na Amazônia brasileira. Revista Brasileira de Ecoturismo, São Paulo, v.7, n.1, p.44-66, 2014.

OLIVEIRA, W. A. Turismo, unidades de conservação e inclusão social: Uma análise da Área de Proteção Ambiental Recifes de Corais (APARC) e Área de Proteção Ambiental Jenipabu (APAJ), RN. Dissertação (Mestrado). Universidade Federal do Rio Grande do Norte, Natal, 2017.

SANCHO, A. Turismo: Alternativa Efetiva de Inclusão Social? Uma reflexão sobre as Políticas Públicas de Turismo no Brasil. Dissertação (Mestrado). Universidade Federal do Rio de Janeiro, Rio de Janeiro, 2007.

SILVEIRA-JUNIOR, W.J.; BOTELHO, E.S. Turismo em áreas protegidas e inclusão social de populações tradicionais: um estudo de caso da Cooperativa de Ecoturismo de Guaraqueçaba (PR). Revista Brasileira de Ecoturismo, São Paulo, v.4, n.3, p.441-462, 2011.

Recebido em: 20-03-2019.

Aprovado em: 06-07-2019.

Versão aprovada para publicação em: 10-08-2019. 